\title{
A Importância da Autonomia dos Estudantes para a Ocorrência de Práticas Epistêmicas no Ensino por Investigação
}

\section{The Importance of Student Autonomy to the Occurrence of Epistemic Practices in the Inquiry-Based Teaching}

\author{
Maíra Batistoni e Silva \\ Brasil \\ Eloísa Cristina Gerolin \\ Brasil \\ Sílvia L. Frateschi Trivelato \\ Brasil
}

Neste trabalho investigamos a relação entre a autonomia dos estudantes para tomar decisões referentes às transformações do conhecimento ao longo do processo investigativo e seu engajamento com práticas epistêmicas numa atividade de ensino baseado em investigação. Partimos das hipóteses de que os momentos com maior diversidade de práticas epistêmicas estariam associados às transformações performadas pelos alunos ao longo do processo investigativo, e que os mesmos momentos teriam alto grau de autonomia dos estudantes. Como procedimento, mapeamos a ocorrência de práticas epistêmicas nas interações discursivas de dois grupos de estudantes ao longo de uma atividade de ensino por investigação sobre dinâmica populacional. A partir desse mapeamento, identificamos os episódios com maior diversidade de práticas epistêmicas e, nestes, analisamos as interações discursivas buscando caracterizar a situação didática que promoveu essa maior diversidade. Nossas análises revelaram que os dois grupos de estudantes conduziram suas investigações de formas distintas, realizando as transformações do conhecimento (dado $\rightarrow$ evidência $\rightarrow$ padrão/modelo $\rightarrow$ explicação) em diferentes momentos e de maneira não-linear. Também tivemos evidências que os momentos de transformações ao longo do processo investigativo eram constituídos por processos de construção de consenso e de decisão. Com apenas uma exceção, a proposição da ação que se converteu em consenso nos grupos fora feita por estudantes, $\mathrm{o}$ que revelou que atuavam com autonomia nesse processo. Concluímos que a ocorrência de uma maior diversidade de práticas epistêmicas se relacionou com os momentos de transformações do conhecimento e com contextos investigativos que promoveram a autonomia dos estudantes para conduzir a investigação.

Palavras-chave: Práticas Epistêmicas; Ensino por Investigação; Autonomia do Estudante. 
In this work, we investigate the relationship between students' autonomy to make decisions and their engagement with epistemic practices in a didactic activity related to inquiry-based teaching. We hypothesized that the episodes with greater diversity of epistemic practices would be associated to the transformations performed by students throughout the inquiry process, and that the same episodes would indicate a high degree of students' intellectual autonomy. We mapped the occurrence of different epistemic practices in the discursive interactions in two student groups during an inquiry-based teaching activity about population dynamics. From this mapping, we identified the episodes with the highest occurrence of epistemic practices and analyzed their discursive interactions in order to characterize the specific didactic situation that promoted this greater occurrence. Our analysis revealed that both groups conducted their investigations in different ways, since they performed the transformations of knowledge (data $\rightarrow$ evidence $\rightarrow$ pattern/model $\rightarrow$ explanation) at different moments and in a nonlinear way. We also had evidence that decision-making processes throughout the inquiry process constituted these moments, as we observed the occurrence of epistemic practices of legitimation (consensus building). In all but one case, it was the students who made the proposition of the action that became a consensus in the groups, what indicates that they acted with autonomy in the decision-making processes. We conclude that the occurrence of a greater diversity of epistemic practices was related to inquiry contexts that promoted students' intellectual autonomy to carry out their investigations.

Keywords: Epistemic Practices; Inquiry-Based Teaching; Student Autonomy.

\section{Introdução}

Nos dias de hoje, nos deparamos diariamente com informações relacionadas às ciências em diversas mídias, dos jornais e revistas impressos às tags nas redes sociais, passando pelo rádio e TV de grande audiência. Esse exacerbado volume de informações vem impondo exigências educacionais no que diz respeito ao ensino de ciências: o acesso à informação científica se amplificou e hoje não está restrito à escola. No entanto, apenas o acesso à informação não garante aos cidadãos a compreensão adequada dos produtos da ciência, tampouco da natureza e do modo de produção do conhecimento científico.

Tal concepção se relaciona à ideia de alfabetização científica, segundo a qual a educação em ciências deve contribuir para a formação de cidadãos capazes de utilizar os saberes, conhecimentos e práticas da cultura científica para modificar o mundo e intervir na sociedade (DeBoer, 2000; Sasseron, \& Carvalho, 2011).

No contexto da alfabetização científica, o ensino das disciplinas científicas deve ampliar as oportunidades de os estudantes aprenderem ciências para além do conhecimento produzido, incluindo aspectos sociais, culturais e epistêmicos que circundam a prática científica (Duschl, 2008). Sob essa perspectiva, alguns autores sugerem que devemos possibilitar que os estudantes conheçam e se apropriem das práticas epistêmicas da comunidade científica (Duschl, 2008; Jiménez-Aleixandre, 2014; 
Kelly, \& Licona, 2018). O engajamento com as práticas epistêmicas pode proporcionar aos estudantes uma compreensão sobre como o conhecimento científico é construído de maneira coletiva por meio de processos de proposição, comunicação, avaliação e legitimação do conhecimento. Visando tal compreensão por parte dos estudantes, Kelly e Duschl (2002) argumentam que as práticas epistêmicas devem compor os objetivos didáticos e, consequentemente, devem ser explicitamente consideradas na concepção de ambientes de aprendizagem de ciências.

Nesse sentido, consideramos o ensino por investigação como uma abordagem didática promissora para a apropriação das práticas epistêmicas, visto que pressupõe a criação de um ambiente de aprendizagem no qual o estudante participe de forma ativa na investigação, valorizando também aspectos epistêmicos e sociais do empreendimento científico.

Reconhecemos, no entanto, que o ensino por investigação pode ser planejado e implementado com diferentes níveis de abertura, o que atribui aos estudantes maior ou menor autonomia para conduzir as etapas do processo investigativo e, consequentemente, pode influenciar sua capacidade de promover o aprendizado dos aspectos epistêmicos e sociais da ciência.

Algumas pesquisas evidenciam uma relação positiva entre o grau de abertura para a atuação dos estudantes e a compreensão adequada do empreendimento científico (Sadeh, \& Zion, 2009, 2012; Zion, \& Medelovici, 2012). No entanto, nenhuma delas relaciona o nível de abertura ao engajamento com práticas epistêmicas e à ocorrência dessas ao longo de uma atividade didática. Assim, este trabalho busca verificar se, no contexto de uma atividade didática planejada com base nos pressupostos do ensino por investigação, há uma relação positiva entre a autonomia dos estudantes e seu engajamento em práticas epistêmicas.

\section{As práticas epistêmicas no ensino de ciências}

Kelly (2008) define práticas sociais como as "ações tipicamente executadas por membros de um grupo baseados em propósitos e expectativas comuns, com valores culturais, ferramentas e significados compartilhados” (p. 99, tradução nossa). Quando essas práticas sociais dizem respeito às formas como membros de uma comunidade propõem, justificam, avaliam e legitimam o conhecimento, essas são denominadas práticas epistêmicas (Kelly, 2008). Ao tratarmos especificamente do conhecimento científico, devemos entender que ele está atrelado às práticas epistêmicas de uma comunidade particular: a comunidade científica de um determinado campo do conhecimento.

Independente da comunidade a qual nos referimos, suas práticas epistêmicas são desenvolvidas em um determinado contexto histórico-cultural e expressas em processos comunicativos utilizando diversas formas de linguagem (Kelly, \& Licona, 2018). Assim, elas se consolidam por meio da interação entre os sujeitos (Kelly, 2008).

Nas últimas duas décadas, temos assistido no campo dos estudos sobre educação 
científica o aumento do número de pesquisas sobre as práticas epistêmicas. De forma geral, tais pesquisas defendem que o engajamento dos estudantes nas práticas epistêmicas representa um aspecto importante da aprendizagem científica, pois possibilita ao estudante uma adequada percepção da dimensão social da ciência, bem como da natureza do conhecimento científico (Duschl, 2008; Jiménez-Aleixandre, Mortimer, Silva, \& Díaz, 2008; Kelly, \& Duschl, 2002; Kelly, \& Licona, 2018; Mortimer, \& Araújo, 2014).

Sendo relevante a ocorrência de práticas epistêmicas no ensino de ciências, torna-se necessário caracterizar as abordagens didáticas que promovam oportunidades para isso. Assim, muitos dos trabalhos sobre essa temática têm como principal objetivo caracterizar as práticas epistêmicas nas ações e discursos dos estudantes e relacioná-las ao contexto didático investigado (Mortimer, \& Araújo, 2014; Sasseron, \& Duschl, 2016; Silva, 2015; Silva, \& Trivelato, 2017).

Nesse cenário, consideramos interessante a estrutura proposta por Kelly e Duschl (2002) para fundamentar a elaboração de atividades didáticas, denominada continuum evidência-explicação (continuum EE). Para a concepção dessa estrutura os autores consideram a investigação científica como um processo contínuo de transformações do conhecimento (dados $\rightarrow$ evidência $\rightarrow$ modelo/padrão $\rightarrow$ explicação) e argumentam que em cada etapa de transformação há uma tomada de decisão que exige o desenvolvimento de critérios de caráter epistêmico.

No continuum EE, o primeiro momento de tomada de decisão é a transformação de dados em evidências (T1); o segundo momento é a transformação das evidências em padrões e modelos (T2); e o terceiro momento de tomada de decisão é a transformação dos padrões e modelos em explicações (T3). Cada uma das transformações representa uma oportunidade para o discurso epistêmico (Kelly, \& Duschl, 2002).

Dessa forma, para promover o engajamento em práticas epistêmicas, a concepção de ambientes de aprendizagem deve considerar a necessidade dos estudantes atuarem nesse continuum EE, participando das transformações e, consequentemente, tomando decisões acerca do que conta como dado, evidência, padrão ou explicação numa determinada investigação científica (Kelly, \& Duschl, 2002).

Por fim, embora Kelly e Duschl (2002) não discutam de forma explícita como deve se dar a atuação dos estudantes no continuum $\mathrm{EE}$, entendemos que a oportunidade para o engajamento em práticas epistêmicas está estritamente associada à autonomia dada aos estudantes, pois para realizarem essas transformações eles precisam estabelecer critérios e, então, tomar decisões referentes ao processo investigativo no qual estão envolvidos.

\section{O ensino por investigação e a aprendizagem epistêmica}

Como a investigação constitui uma prática central na construção do conhecimento científico (Jiménez-Aleixandre, \& Crujeiras, 2017; Osborne, 2016; Scarpa, Sasseron, \& Silva, 2017), uma abordagem didática que oportuniza a apropriação das práticas 
epistêmicas é o ensino por investigação (Kelly, \& Licona, 2018).

Embora o ensino por investigação exista como uma proposta para o ensino de ciências há várias décadas, o entendimento de como ele deve participar da educação científica já se transformou bastante. Dewey (1919) e Schwab (1962) entendiam o ensino por investigação como uma representação da ciência tal como a praticada pelos cientistas. Mais recentemente, os que apoiam o ensino por investigação visam a alfabetização científica, e o concebem como uma das estratégias que fomentam a compreensão da natureza da ciência e a possibilidade de aplicar conhecimentos e modos de agir na resolução de problemas autênticos.

Há na literatura uma profusão de definições para o ensino por investigação (Anderson, 2002). Minner e colegas (2010) realizaram uma revisão de 20 anos de produção científica acerca desse tópico e consideraram a descrição dos principais aspectos da investigação em sala de aula do National Research Council (2000) como uma síntese adequada do atual entendimento da literatura sobre o tema. Segundo o NRC (2000), numa investigação no contexto escolar os estudantes: i. Estão envolvidos em questões cientificamente orientadas; ii. Utilizam evidências para avaliar explicações científicas; iii. Formulam explicações científicas a partir de evidências; iv. Avaliam suas explicações à luz de explicações alternativas; v. Comunicam e justificam as explicações propostas.

Essa síntese destaca os principais aspectos do ensino por investigação sob a perspectiva do aluno, o que evidencia a importância, nessa abordagem didática, de se colocar o estudante num papel ativo na construção de seu conhecimento. O nível de abertura para a atuação dos estudantes ou de direcionamento do professor pode variar bastante, a depender dos objetivos educacionais, disponibilidade de tempo, conceitos a serem trabalhados, características dos estudantes, relações com a turma e experiência do docente (Scarpa, \& Silva, 2013).

O nível de abertura para a atuação dos estudantes nas atividades de ensino por investigação vem sendo caracterizado desde os anos 1970 (Banchi, \& Bell, 2008; Carvalho, 2012; Tamir, 1977; Zion, \& Medelovici, 2012). De maneira geral, classificase a investigação em três níveis de abertura, a depender da autonomia oferecida aos estudantes nas etapas do processo: estruturada, guiada e aberta.

$\mathrm{Na}$ investigação estruturada, cabe ao professor definir o problema, oferecer o conjunto de dados e definir as evidências relevantes; aos estudantes cabe construir as explicações para os dados coletados e estabelecer a forma de comunicação das conclusões. $\mathrm{Na}$ investigação guiada, o professor oferece a pergunta de caráter científico e os estudantes conduzem as demais etapas da investigação de forma autônoma. Já na investigação aberta, o professor define o tema a ser investigado e os estudantes decidem desde a pergunta até a forma de comunicação de suas conclusões (Banchi, \& Bell, 2008; Zion \& Medelovici, 2012).

As pesquisas têm evidenciado que para o desenvolvimento do raciocínio científico e para a adequada compreensão do empreendimento científico, a investigação 
estruturada não seria a melhor escolha (Zion, \& Medelovici, 2012). Estudos que compararam a efetividade de atividades guiadas e abertas em aulas de Biologia para estudantes do ensino médio indicaram que as investigações abertas propiciaram uma melhor compreensão do dinamismo da investigação científica, melhor habilidade procedimental, além de maior satisfação pessoal dos estudantes (Sadeh, \& Zion, 2009; 2012). Outro estudo comparativo evidenciou que as atividades experimentais abertas, realizadas por estudantes de química também do ensino médio, propiciaram maior e melhor argumentação dos alunos do que as atividades estruturadas (Katchevich; Hofstein, \& Mamlok-Naaman; 2013).

Esses trabalhos vêm fornecendo pistas sobre a importância da autonomia dos estudantes para uma aprendizagem das ciências que contemple não apenas seu aspecto conceitual, mas também seus aspectos epistêmicos e sociais, embora nenhum deles relacione o nível de abertura do ensino por investigação à ocorrência de práticas epistêmicas.

Neste trabalho, pretendemos contribuir com uma maior compreensão sobre a relação entre engajamento em práticas epistêmicas, as transformações do conhecimento necessárias ao processo investigativo e o nível de abertura para atuação dos estudantes no ensino por investigação.

Para tanto, analisamos um ambiente de aprendizagem concebido com base no continnum EE e que, desta forma, promovia um contexto investigativo no qual os estudantes precisavam atuar nas transformações do conhecimento (dados $\rightarrow$ evidência $\rightarrow$ modelo/padrão $\rightarrow$ explicação). A pergunta científica que desencadeou a investigação no ambiente escolar foi fornecida pela professora e, considerando a caracterização dos níveis de abertura citada anteriormente, tratou-se de uma atividade de ensino por investigação guiado.

Examinamos as interações discursivas identificando e quantificando a ocorrência de diferentes práticas epistêmicas numa sequência de aulas nas quais os estudantes estavam trabalhando em grupo na resolução da pergunta de investigação. Esse primeiro exame nos forneceu um panorama da variação da ocorrência de práticas epistêmicas ao longo da sequência de aulas. Tal variação nos conduziu a uma nova análise das interações discursivas, focando nos episódios com maior ocorrência de práticas epistêmicas para caracterizar a situação didática específica que promoveu esta maior ocorrência.

Embora consideremos a estrutura proposta pelo continuum EE promissora, reconhecemos que o processo investigativo pode se desenvolver de maneiras distintas, a depender do que está sendo investigado (Hodson, 2014), bem como das condições disponibilizadas pelo contexto escolar. Nas atividades de ensino por investigação desenvolvidas com baixo nível de abertura para a atuação dos estudantes, as transformações mais relevantes do continuum EE podem ser definidas a priori pelo professor e os estudantes apenas as executam. Nessa situação, poderíamos observar as transformações previstas no continuum EE sem que isso possibilitasse a ocorrência de práticas epistêmicas, visto que não haveria autonomia para os estudantes tomarem as 
decisões necessárias às transformações do conhecimento no processo investigativo.

Dessas considerações surgiram as hipóteses que orientaram esta pesquisa: A primeira delas é que os episódios de maior ocorrência de práticas epistêmicas devem coincidir com os momentos referentes às transformações do continuum EE; A segunda é que, nos episódios de maior ocorrência de práticas epistêmicas, encontraremos situações nas quais os estudantes dispõem de autonomia para tomar as decisões referentes às necessárias transformações do processo de investigação.

As perguntas de pesquisa que guiaram este estudo foram:

1. Qual a relação entre os episódios com maior ocorrência de diferentes práticas epistêmicas e as transformações do continuum EE na atividade de ensino por investigação analisada?

2. Qual a relação entre os episódios com maior ocorrência de diferentes práticas epistêmicas e a autonomia dos estudantes para a tomada de decisão referente às transformações do conhecimento ao longo da investigação?

\section{Aspectos metodológicos}

A abordagem metodológica deste trabalho está em consonância com as abordagens qualitativas de pesquisa, visto que procura compreender, interpretar e descrever fenômenos socioeducativos considerando o contexto em que esses acontecem (Lüdke, \& André, 2014). Essa perspectiva requer que a observação e coleta dos dados ocorram em contextos naturais e reais do cotidiano, como forma de acessar um conhecimento aprofundado do fenômeno (Silverman, 2000). Embora o estudo seja qualitativo em sua natureza, buscamos na abordagem quantitativa alguns procedimentos descritivos para ampliar a caracterização do fenômeno investigado.

A sequência didática que possibilitou a coleta dos dados foi desenvolvida no decorrer de 14 aulas (7 semanas), ministradas entre o final do $1^{\circ}$ semestre e o início do $2^{\circ}$ semestre de 2013 para estudantes de Biologia do $1^{\circ}$ ano do Ensino Médio (14/15 anos) de uma escola pública da região oeste da cidade de São Paulo. O tema norteador de toda a sequência didática foi dinâmica populacional, conteúdo previsto para o $1^{\circ}$ ano do Ensino Médio segundo a Proposta Curricular do Estado de São Paulo (SEE-SP, 2008). Uma descrição detalhada da sequência didática pode ser encontrada em Silva e Trivelato (2016) e uma síntese das atividades e seus respectivos objetivos didáticos encontra-se da Figura 1. 


\begin{tabular}{|c|c|}
\hline Aula $(s)$ & Descrição da atividade e dos respectivos objetivos didáticos \\
\hline \multirow[b]{2}{*}{$\begin{array}{l}01,02 \mathrm{e} \\
03\end{array}$} & $\begin{array}{l}\text { Atividade I: Leitura e interpretação do artigo Demografia de elefantes-marinhos, 1911- } \\
\text { 1982. Traduzido de Cooper e Stewart (1983). }\end{array}$ \\
\hline & $\begin{array}{l}\text { Objetivos: Contextualizar o estudo da dinâmica populacional a partir do estudo de caso } \\
\text { dos elefantes-marinhos da costa da Califórnia. Introduzir os conceitos de natalidade, } \\
\text { mortalidade, emigração, imigração, capacidade suporte e conservação. }\end{array}$ \\
\hline \multirow{2}{*}{04} & $\begin{array}{l}\text { Atividade II: Produção de argumentos para justificar a conclusão do artigo Demografia } \\
\text { de elefantes-marinhos, 1911-1982. }\end{array}$ \\
\hline & $\begin{array}{l}\text { Objetivos: Fomentar a construção de argumentos com justificativas de diferentes } \\
\text { naturezas. }\end{array}$ \\
\hline & Atividade III: Início da investigação sobre dinâmica populacional de Lemna sp. \\
\hline 05 & $\begin{array}{l}\text { Objetivos: Apresentar a espécie como modelo para estudos de dinâmica populacional. } \\
\text { Apresentar a pergunta científica para investigação e estimular o início da coleta de dados } \\
\text { pelos estudantes. }\end{array}$ \\
\hline \multirow[b]{2}{*}{06 e 07} & Atividade IV: Exercício de amostragem para estimar tamanho populacional. \\
\hline & $\begin{array}{l}\text { Objetivos: Apresentar e estimular o uso de diferentes métodos de amostragem para estimar } \\
\text { tamanho das populações biológicas. }\end{array}$ \\
\hline 08 & $\begin{array}{l}\text { Atividade V: Aula expositiva dialogada sobre dinâmica populacional. } \\
\text { Objetivos: Definir os conceitos de natalidade, imigração, mortalidade, emigração, } \\
\text { potencial biótico, resistência do meio, capacidade biótica e apresentar o modelo logístico } \\
\text { de crescimento populacional. }\end{array}$ \\
\hline \multirow{2}{*}{09} & Atividade VI: Resolução de exercícios sobre dinâmica populacional. \\
\hline & Objetivos: Revisar e sistematizar os conceitos referentes ao tema dinâmica populacional. \\
\hline $\begin{array}{l}10,11 \\
12,13 \text { e } \\
14\end{array}$ & $\begin{array}{l}\text { Atividade III (continuação): Investigação sobre dinâmica populacional de Lemna sp. } \\
\text { Objetivos: Propiciar ambiente de aprendizagem no qual os estudantes possam analisar os } \\
\text { dados coletados (fotos da população de Lemna sp.) e responder à pergunta de investigação } \\
\text { por meio de um relatório. }\end{array}$ \\
\hline
\end{tabular}

Figura 1. Descrição das atividades e seus respectivos objetivos didáticos da sequência didática sobre dinâmica populacional. As aulas destacadas constituíram a atividade de ensino por investigação analisada neste trabalho

A atividade adotada como objeto deste estudo (Atividade III) foi concebida com base nos pressupostos do ensino por investigação bem como do continuum EE proposto por Kelly e Duschl (2002). A atividade em questão tinha como objetivo central engajar os estudantes num processo investigativo cuja pergunta desencadeadora era "O que acontece com uma população biológica após a colonização por alguns indivíduos de um ambiente com as condições ideais para o desenvolvimento da espécie?” e cuja a produção final dos estudantes deveria ser a elaboração de um relatório científico para comunicar o processo investigativo.

Cada grupo de estudantes acompanhou a dinâmica de uma população de Lemna sp. (diminuta planta aquática com alta capacidade de reprodução por brotamento) ao longo de 15 dias, realizando registros fotográficos diários do recipiente com sua 
respectiva população, o que explica a distância entre a aula que inicia a investigação (Aula 05) e as aulas nas quais os estudantes produziram o relatório científico (Aulas 10 a 14).

As aulas analisadas neste trabalho foram as cinco últimas da sequência didática (Aulas 10 a 14), nas quais os estudantes estavam produzindo o relatório científico e performando o continuum EE. A Figura 2 representa a estrutura do continuum EE com a descrição das transformações e das decisões realizadas pelos estudantes na atividade de ensino por investigação analisada neste trabalho.

\section{As transformações do conhecimento e os momentos de tomada de decisão referentes à investigação: oportunidades de engajamento em práticas epistêmicas}

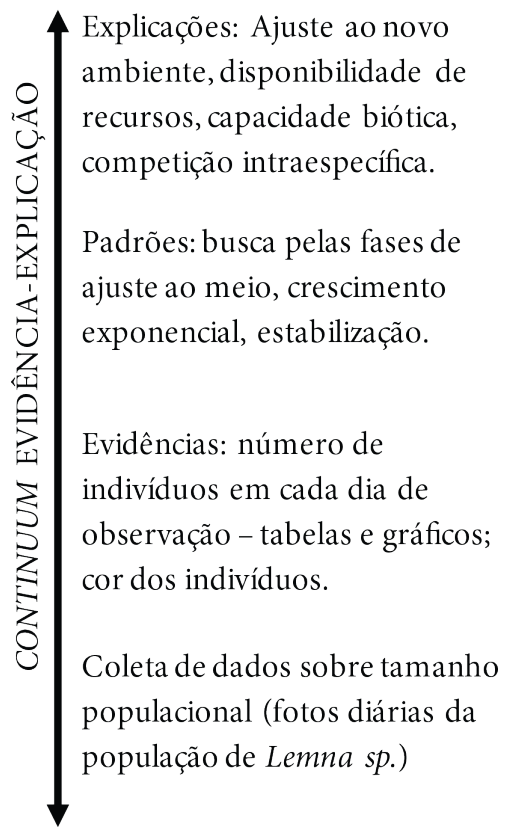

Exemplos de decisões a serem tomadas pelos estudantes

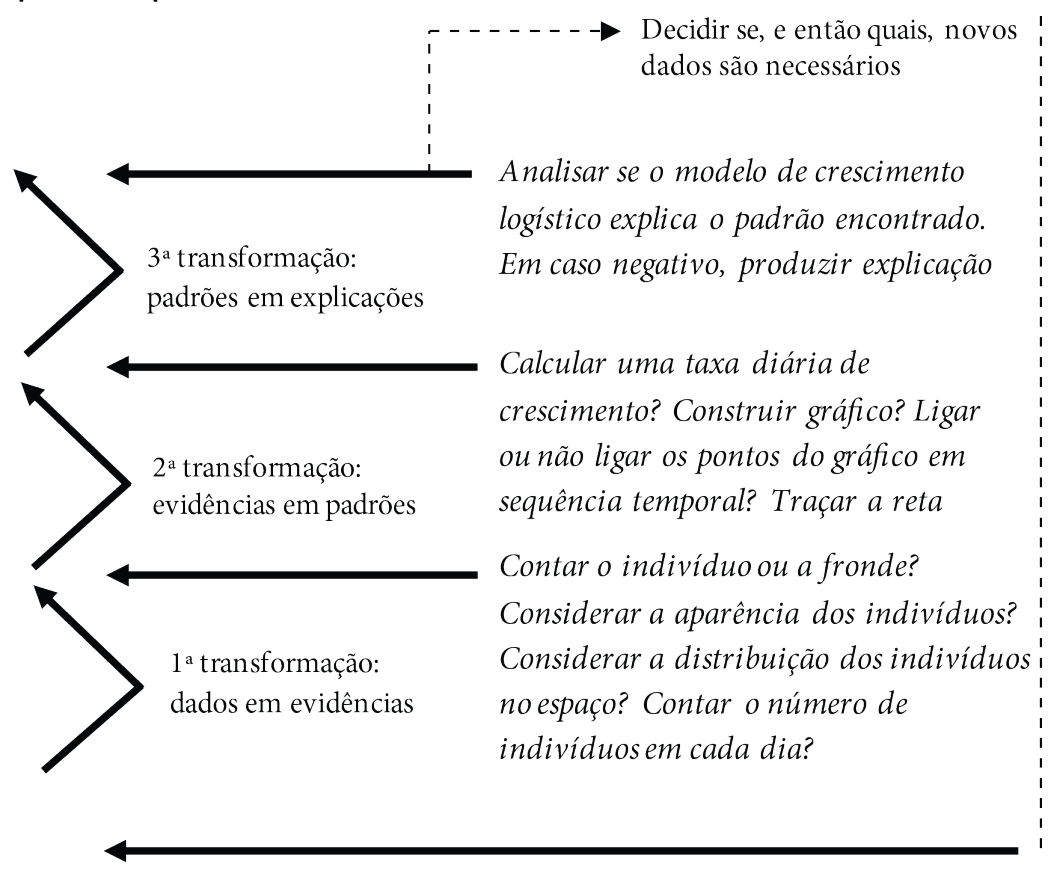

Figura 2. Esquema da investigação realizada pelos alunos de acordo com a estrutura do continnum EE proposta por Kelly e Duschl (2002)

Nossos dados consistem em interações discursivas registradas por meio de gravações em áudio e vídeo do grupo sala, da professora e dos pequenos grupos de trabalho constituídos por três ou quatro estudantes.

A sala de aula como um todo faz parte do contexto investigado, porém, neste estudo, focamos nossa análise em dois grupos de estudantes (identificados por A e C) que trabalharam em conjunto na atividade analisada. $\mathrm{O}$ critério para seleção desses dois grupos consistiu na integridade e disponibilidade dos dados, ou seja, nosso estudo incidiu sobre os grupos que possuíam vídeo-gravações em todas as aulas da atividade didática objeto de interesse desta pesquisa. É importante mencionar que dentre os dados selecionados há interações discursivas entre os alunos dos grupos A e C com e sem a participação da professora.

As interações discursivas registradas foram transcritas após a delimitação dos 
episódios, definidos como um extrato do discurso da sala de aula que tem limites em função de temas/conceitos ou tarefas que constituem a dinâmica das atividades escolares (Silva, \& Mortimer, 2005). O episódio não emerge naturalmente; como ocorre com outras unidades quando se analisam interações discursivas, sua delimitação é um ato interpretativo, que se dá na interação com os dados empíricos (Martins, 2006). Com a adoção da unidade de episódio pudemos separar as interações discursivas que estavam relacionadas ao foco da atividade didática daquelas que tratavam de outros assuntos (p. e. conversas pessoais ou brincadeiras entre os estudantes), delimitar a entrada ou a saída de um interlocutor da interação discursiva (professora ou monitor) e também identificar as mudanças de ações dos estudantes. No contexto específico desta pesquisa, como cada grupo de estudantes trabalhava sem a presença constante da professora para ditar um ritmo e uma sequência de tarefas, as interações discursivas dos sujeitos envolvidos transitavam entre diferentes assuntos ou ações, sendo que alguns desses não tinham relação com a atividade didática; desta forma, o número de episódios varia entre as aulas e entre os grupos analisados.

As transcrições foram realizadas com o auxílio do software V-Note e a conversação foi organizada em turnos de fala, que representam os momentos nos quais os participantes de uma interação discursiva se alternam entre os papéis de falante e ouvinte (Galembeck, 2010). Os extratos dos turnos conversacionais que evidenciam e ilustram aspectos discutidos neste trabalho foram editados objetivando facilitar o entendimento das interações discursivas. Tal edição consistiu em supressão de falas paralelas que se interpõem, de marcas da oralidade e de expressões e gírias.

Os estudantes e seus responsáveis foram informados sobre os objetivos e procedimentos da presente pesquisa. As autorizações de participação foram consentidas por meio da assinatura do Termo de Consentimento Livre e Esclarecido (TCLE) e do Termo de Assentimento Livre e Esclarecido (TALE). Além disso, todos os nomes foram alterados a fim de proteger o anonimato dos estudantes.

Nossas categorias de análise foram concebidas por meio de um ciclo dinâmico de interlocução entre as categorias de práticas epistêmicas para o ensino por investigação propostas por Kelly e Licona (2018) e nossos dados. Isto foi feito partindo do pressuposto de que as práticas epistêmicas são desenvolvidas de forma interacional em um determinado contexto sociocultural, sendo mutáveis e dependentes das concepções epistêmicas de uma determinada comunidade, consideramos que não há um conjunto limitado e estático de práticas epistêmicas. Portanto, algumas categorias propostas por Kelly e Licona (2018) foram suprimidas, ao passo que novas categorias foram constituídas, considerando a natureza da investigação que estava sendo realizada pelos estudantes. Na Figura 3, apresentamos as categorias de análise das práticas epistêmicas utilizadas. 


\begin{tabular}{|c|c|}
\hline \multicolumn{2}{|c|}{ Práticas epistêmicas } \\
\hline \multirow{6}{*}{ Proposição } & 1. Elaborar questões científicas \\
\hline & 2. Planejar investigações para responder questões científicas \\
\hline & 3. Fazer observações \\
\hline & 4. Identificar quais evidências são relevantes para a investigação \\
\hline & 5. Construir evidências a partir dos dados \\
\hline & 6. Lidar com problemas e situações anômalas \\
\hline \multirow{4}{*}{ Comunicação } & 1. Construir explicações para os aspectos científicos \\
\hline & 2. Construir inscrições literárias \\
\hline & 3. Utilizar inscrições literárias \\
\hline & 4. Escrever um relatório científico \\
\hline Avaliação & $\begin{array}{l}\text { 1. Avaliar os méritos de uma afirmação, evidência, explicação ou inscrição } \\
\text { literária }\end{array}$ \\
\hline \multirow{3}{*}{ Legitimação } & 1. Construir consenso de grupo sobre procedimentos \\
\hline & $\begin{array}{l}\text { 2. Construir consenso de grupo sobre as explicações relacionadas aos aspectos } \\
\text { científicos }\end{array}$ \\
\hline & 3. Reconhecer conhecimentos relevantes para a comunidade epistêmica \\
\hline
\end{tabular}

Figura 3. Rubrica para a categorização das práticas epistêmicas. As categorias em itálico correspondem àquelas que foram constituídas para este estudo

O resultado do processo de categorização das interações discursivas foi validado por três duplas de pesquisadores que trabalharam independentemente no processo de categorização de uma amostra aleatória de episódios do conjunto de dados. Após essa primeira etapa de validação, houve um segundo processo de revisão realizado pelas autoras desta pesquisa, que resultou em $86 \%$ de convergência das categorizações realizadas.

Posteriormente às categorizações, adotando os episódios como unidade de análise, atribuímos um (1) ponto para cada prática epistêmica diferente encontrada. Esse procedimento nos possibilitou quantificar a diversidade das categorias de práticas epistêmicas nos episódios analisados, isto é, episódios que apresentaram a ocorrência de uma única categoria de prática epistêmica receberam apenas um ponto; episódios que apresentaram duas categorias de práticas epistêmicas receberam dois pontos, e assim sucessivamente.

No excerto de interação discursiva da Figura 4 exemplificamos como tal procedimento foi realizado: no recorte apresentado, categorizamos a interação na categoria de práticas epistêmicas "Proposição - Lidar com problemas e situações anômalas" (P6); as duas falas da Camila trazem para o grupo um outro aspecto que aqui foi categorizado como "Avaliação - Avaliar os méritos de uma afirmação, evidência, explicação ou inscrição literária" (A1). Assim, caso o excerto representasse a totalidade dos turnos do episódio, teríamos 1 ponto atribuído à prática epistêmica "P6" e 1 ponto atribuído à prática epistêmica "A1" independentemente do número de turnos que foram associados à cada uma das categorias e, dessa forma, o episódio receberia dois (2) pontos. 


\begin{tabular}{|c|c|c|c|}
\hline Locutor & Transcrição & \multicolumn{2}{|c|}{ Práticas epistêmicas } \\
\hline Juliana & Camila, deu 300 no meu... & & \multirow{9}{*}{$\begin{array}{l}\text { Proposição: Lidar } \\
\text { com problemas e } \\
\text { situações anômalas. }\end{array}$} \\
\hline Ana Paula & Deu 300? & & \\
\hline Camila & $\begin{array}{l}\text { Caramba gente! A diferença é meio } \\
\text { grande... }\end{array}$ & Avaliação & \\
\hline Ana Paula & $\begin{array}{l}\text { Mas é porque eu contei as que também } \\
\text { estão escondidinhas aqui ó... }\end{array}$ & & \\
\hline Professora & Não, essas aqui são reflexo... & & \\
\hline Ana Paula & Poxa... & & \\
\hline Juliana & Então é por isso... & & \\
\hline Camila & $\begin{array}{l}\text { Olha assim... Meu Deus, o gráfico tem } \\
\text { alguma coisa errada... }\end{array}$ & Avaliação & \\
\hline Ana Paula & $\begin{array}{l}\text { Então... Conta esse daqui de novo } \\
\text { também... }\end{array}$ & & \\
\hline
\end{tabular}

Figura 4. Excerto conversacional com exemplificação de categorização das práticas epistêmicas

Essa análise nos permitiu elaborar um panorama da variação da ocorrência de diferentes práticas epistêmicas em cada grupo de estudantes ao longo dos episódios (Figuras 7 e 8). Esse panorama nos conduziu à uma segunda análise, na qual destacamos aqueles episódios com maior diversidade de práticas epistêmicas e examinamos novamente suas interações discursivas, buscando agora identificar as transformações do continuum EE e caracterizar o grau de autonomia que os estudantes tiveram para tomar as decisões necessárias às transformações do conhecimento no decorrer da investigação.

Para o processo de identificação das transformações do continuum EE, utilizamos como rubrica os descritores das ações dos estudantes propostos por Kelly e Duschl (2002) em cada transformação. Tais descritores estão organizados na Figura 5.

\begin{tabular}{|l|l|}
\hline $\begin{array}{l}\text { Transformação do } \\
\text { continuum EE }\end{array}$ & Descrição da ação dos estudantes quando a realizam \\
\hline T1 (dado $\rightarrow$ evidência) & $\begin{array}{l}\text { Consideram os dados como evidências, como artefatos, como } \\
\text { irrelevantes ou como anômalos }\end{array}$ \\
\hline T2 (evidência $\rightarrow$ padrão) & Selecionam estratégias e ferramentas para identificar padrões/modelos \\
\hline T3 (padrão $\rightarrow$ explicação) & Selecionam teorias ou explicações para explicar os padrões / modelos \\
\hline
\end{tabular}

Figura 5. Rubrica para localização das transformações T1, T2 e T3 do continuum EE

Para definir o nível de abertura para a atuação dos estudantes, retomamos as interações discursivas a fim de localizar momentos nos quais os estudantes tomavam decisões e caracterizar a ação dos estudantes e da professora quando esta participava da interação. Iniciamos a análise procurando, nos diálogos dos episódios, a ocorrência de práticas de legitimação, as quais, em nossa rubrica, correspondem a: Construir consenso de grupo sobre procedimentos, Construir consenso de grupo para explicações científicas e Reconhecer conhecimentos relevantes na comunidade epistêmica. Consideramos essas práticas como rubrica pois tomar decisões referentes ao processo de investigação em um contexto de trabalho em grupo implica em construir consensos com base em critérios 
estabelecidos coletivamente. Posteriormente, identificamos a participação ou não da professora ou do monitor (sujeitos de autoridade epistêmica) e os sujeitos que propõem a ação que posteriormente é assumida como consenso nesses excertos conversacionais.

Identificados os excertos conversacionais que correspondem às nossas rubricas, selecionamos alguns deles para ilustrar nossas discussões. Como consideramos a ocorrência de práticas epistêmicas por episódio, os excertos aqui apresentados são ilustrativos da ocorrência de apenas algumas categorias de práticas epistêmicas, visto que não representam a integralidade dos episódios.

\section{Resultados e discussão}

As Figuras 5 e 6 mapeiam a ocorrência de diferentes categorias de práticas epistêmicas nos episódios de interação distribuídos no eixo horizontal em sequência temporal. Cada coluna representa a ocorrência de práticas epistêmicas em um episódio e as colunas em vermelho equivalem aos episódios com mais de quatro categorias de práticas epistêmicas (adotamos quatro como o número de corte para considerar grande diversidade de categorias de práticas epistêmicas). A Figura 5 refere-se ao mapeamento do grupo A e a Figura 6 ao mapeamento do grupo C.

De acordo com os gráficos, os dois grupos vivenciaram, ao longo das aulas analisadas, momentos (episódios) nos quais ocorreram maior e menor diversidade de práticas epistêmicas. No entanto, em ambos os grupos, poucos foram os episódios com ocorrência de mais de quatro práticas (colunas destacadas em vermelho).

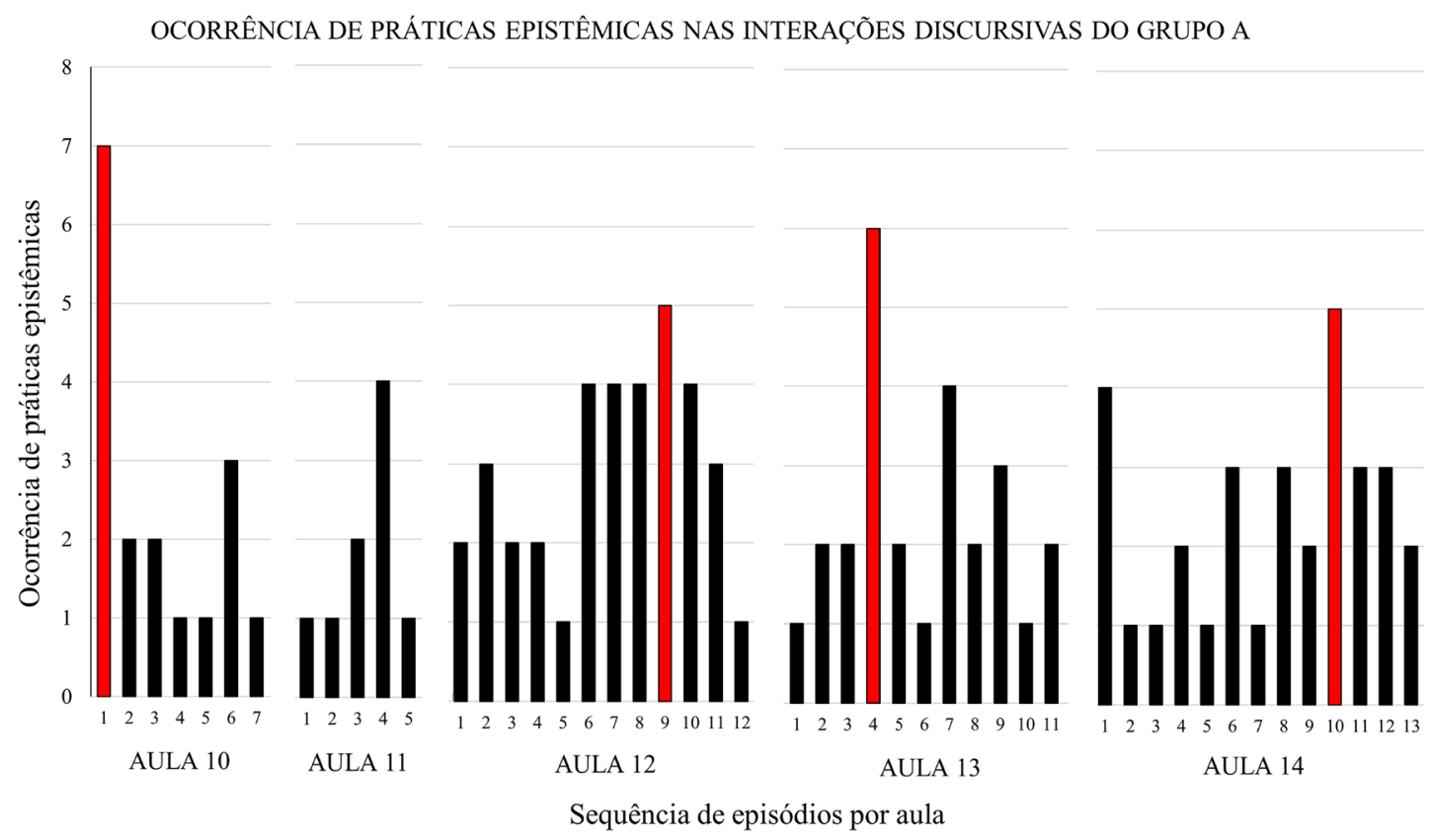

Figura 5. Ocorrência das diferentes categorias de práticas epistêmicas em cada episódio de interação discursiva do grupo A. Os episódios e as aulas estão dispostos no eixo em ordem cronológica 


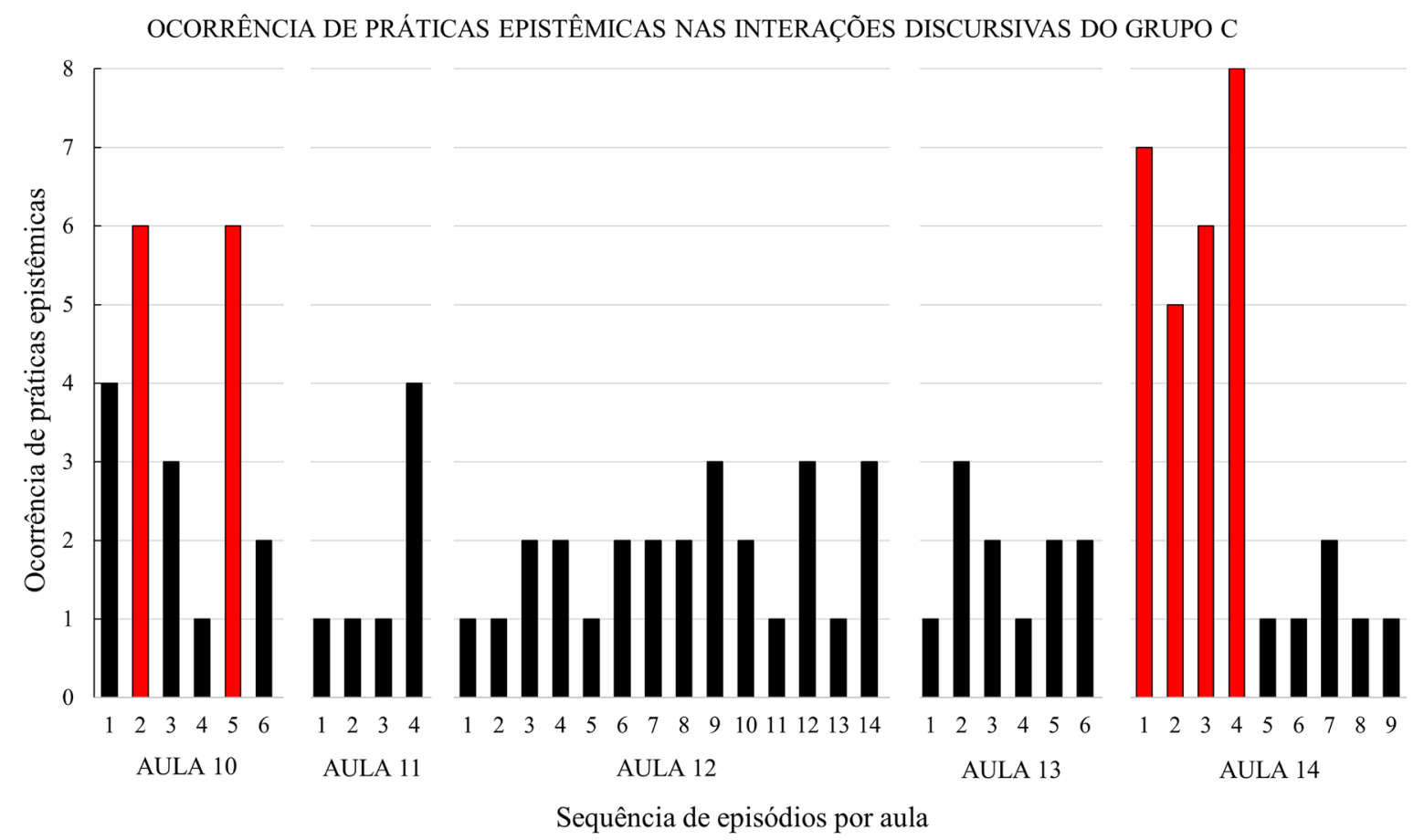

Figura 6. Ocorrência das diferentes categorias de práticas epistêmicas em cada episódio de interação discursiva do grupo C. Os episódios e as aulas estão dispostos no eixo em ordem cronológica

\section{As transformações do continuum EE na atividade didática analisada}

Convergindo com as pesquisas que defendem que o engajamento dos estudantes nas práticas epistêmicas representa um aspecto importante da aprendizagem científica (Duschl, 2008; Jiménez-Aleixandre et al., 2008; Kelly, \& Duschl, 2002; Kelly, \& Licona, 2018; Mortimer, \& Araújo, 2014), preocupamo-nos em analisar os episódios com maior ocorrência de diferentes práticas epistêmicas para caracterizar o contexto didático associado a eles.

Essa análise nos revelou que os episódios com maior ocorrência das diferentes práticas epistêmicas continham interações que correspondiam ao descritor de pelo menos uma das transformações do continuum EE, conforme apresentado na Figura 7.

A evidência de que os estudantes estão envolvidos em transformações do continnum EE nos episódios de maior ocorrência de práticas epistêmicas indica a validade de nossa primeira hipótese, elaborada a partir do próprio modelo construído por Kelly e Duschl (2002).

A seguir, apresentamos uma descrição de como se caracterizaram as transformações T1, T2 e T3 do continuum EE na atividade de ensino por investigação analisada neste trabalho e como se constituíram especificamente nos grupos A e C. 


\begin{tabular}{|c|c|c|c|}
\hline \multicolumn{2}{|c|}{ Grupo A } & \multicolumn{2}{c|}{ Grupo C } \\
\hline $\begin{array}{l}\text { Episódios com } \\
\text { maior ocorrência de } \\
\text { práticas epistêmicas }\end{array}$ & $\begin{array}{l}\text { Transformações } \\
\text { do continuum EE } \\
\text { evidenciadas nas } \\
\text { interaçóes discursivas }\end{array}$ & $\begin{array}{l}\text { Episódios com } \\
\text { maior ocorrência } \\
\text { de práticas } \\
\text { epistêmicas }\end{array}$ & $\begin{array}{l}\text { Transformações } \\
\text { do continuum EE } \\
\text { evidenciadas nas } \\
\text { interações discursivas }\end{array}$ \\
\hline Aula 10 - EP 1 & T1 & Aula 10 - EP 2 & T1 \\
\hline Aula 12 - EP 9 & T2 - T1 & Aula 10 - EP 5 & T2 \\
\hline Aula 13 - EP 4 & T2 - T1 - T2 & Aula 14 - EP 1 & T3 \\
\hline Aula 14- EP 10 & T3 - T2 - T3 & Aula 14 - EP 2 & T3 \\
\hline & & Aula 14 - EP 3 & T3 \\
\cline { 2 - 4 } & & Aula 14 - EP 4 & T3 - T2 - T3 \\
\cline { 2 - 4 }
\end{tabular}

Figura 7. Relação entre os episódios com maior ocorrência de práticas epistêmicas e as transformações do continuum EE para os grupos A e C. Quando ocorreu mais de uma, as transformações foram representadas no quadro em ordem cronológica

\section{Transformação de dados em evidências (T1)}

No contexto desta atividade didática, entendemos que a transformação de dados em evidências corresponde ao processo de ler e interpretar os registros fotográficos que continham informações sobre a população de Lemna sp. e seu respectivo microambiente em cada dia de coleta de dado buscando reconhecer e produzir evidências (número de indivíduos, cor e outros aspectos visíveis das plantas, por exemplo) que permitissem aos alunos descrever qualitativamente ou quantitativamente o que estava acontecendo com a população ao longo do tempo.

Essa transformação compreende processos/momentos de tomada de decisão nos quais os estudantes têm de construir consenso para decidir o que conta como evidência na investigação.

\section{Grupo A}

Analisando o grupo A, encontramos excertos de interação discursiva que se enquadram na rubrica da transformação de dados em evidências (T1) em três episódios com mais de quatro categorias de práticas epistêmicas.

Na Aula 10 - EP1, as alunas explicitaram a decisão de contar os indivíduos de Lemnas, optando por construir evidências quantitativas a respeito de sua população: "Então vamos contar..." "Cada uma conta um dia". Em um segundo momento as alunas discutiram sobre o que seria considerado para estimar o tamanho da população: "Peraí, mas uma plantinha parece que tem três... Eu conto cada folhinha?" "Cada folhinha".

Já na Aula 12 - EP9, as alunas encontraram um erro de contagem que se devia à contabilização dos reflexos das plantas no recipiente do microambiente: "Caramba gente! A diferença é meio grande...”. Esses reflexos foram contabilizados como folhas, gerando um dado anômalo, que, com a percepção do erro cometido, passou a ser um artefato: "Mas é porque eu contei as que também estão escondidinhas aqui ó...." Ao perceber esse 
erro, as alunas decidiram refazer a contagem das folhas em alguns registros fotográficos.

Por fim, na Aula 13 - EP4, enquanto construíam um rascunho do gráfico da dinâmica populacional, as alunas notaram um dado anômalo que logo foi reconhecido como um erro, visto que haviam esquecido de somar o número de folhas brancas para obter o número total de folhas.

\section{Grupo C}

Na Aula 10 - EP2, o grupo C passou por um processo bastante similar ao do Grupo A. Nos turnos conversacionais deste grupo, observamos que já havia a decisão de quantificar o número de indivíduos de Lemna sp.. Assim como no grupo A, este grupo também discutiu se seria a folha ou o indivíduo a ser contabilizado: "Como vai contar? Vai ser muito difícil contar isso aqui... É por folha?" "É..."

\section{Transformação de evidências em padrões e modelos (T2)}

A transformação de evidências em padrões e modelos nesta atividade de ensino por investigação ocorreu quando os alunos tiveram de representar suas evidências de maneira articulada para que pudessem reconhecer e visualizar padrões que lhes permitissem interpretar o que aconteceu com a população de Lemnas ao longo dos dias de observação.

Como todos os grupos optaram por produzir evidências quantitativas, o processo/ momento de tomada de decisão nessa transformação consistiu na construção de um consenso para a escolha de uma inscrição literária que possibilitasse a obtenção de um panorama da dinâmica da população ao longo do tempo.

\section{Grupo A}

Na Aula 12 - EP 9, as alunas iniciaram a construção de um rascunho de gráfico para visualizar padrões / modelo nas evidências já constituídas (número de folhas verdes e número de folhas pretas e brancas em cada dia).

Entretanto, na Aula 13 - EP 4, as alunas adotaram a construção de gráficos como estratégia para visualizar padrões/modelos. Em seguida, discutiram sobre o número de gráficos necessários para representar o fenômeno a partir das evidências construídas e, junto com a professora, decidiram construir um único gráfico para indivíduos vivos (folhas com coloração verde) e indivíduos mortos (folhas com coloração preta ou branca). Posteriormente, devido a problemas na diferença de escalas necessárias para representar as evidências no mesmo gráfico, as estudantes optaram por construir dois gráficos separadamente.

$\mathrm{Na}$ Aula 14 - EP 10, enquanto buscavam explicações para os padrões identificados, uma das alunas notou um equívoco sobre a visualização de um declínio populacional ao final da investigação. Utilizando o próprio gráfico como instrumento, as alunas perceberam um novo padrão: a população estava crescendo "em zigue-zague". 


\section{Grupo C}

Na aula 10 - EP 5, o grupo também decidiu construir um gráfico para visualizar padrões/modelos. Em seguida, o grupo passou a tomar decisões sobre o próprio gráfico, discutindo que notação seria utilizada para representar a ausência de evidências ao longo da reta que deveria ser traçada (aos finais de semana não havia registro de dados).

$\mathrm{Na}$ aula 14 - EP 4, enquanto discutiam uma possível explicação para os padrões já identificados, a professora simulou a construção de uma reta média no gráfico já construído pelo grupo, possibilitando que os estudantes visualizassem outro padrão: o declínio da população de Lemnas seguido de um período de estabilização nos últimos dias da investigação.

\section{Transformação de padrões e modelos em explicações (T3)}

$\mathrm{Na}$ atividade didática, consideramos que a transformação de padrões e modelos em explicações ocorreu quando os alunos tiveram de relacionar os padrões reconhecidos com conhecimentos teóricos e/ou observações empíricas para explicar e justificar a ocorrência de tais padrões.

\section{Grupo A}

$\mathrm{Na}$ Aula 14 - EP 10, pudemos inferir que o grupo optou por justificar os padrões e evidências encontrados com fatores empíricos. O grupo considerou a alta incidência de luz para justificar o alto crescimento da população. Vimos também que o grupo comparou o fator empírico de incidência luminosa com o de outro grupo para justificar sua influência no crescimento de sua população.

\section{Grupo C}

$\mathrm{Na}$ Aula 14 - EP 1, o monitor esclareceu que os estudantes precisavam propor explicações para os padrões encontrados. Um dos estudantes propôs como explicação a influência do clima, mas foi questionado por uma das colegas: "Mas você lembra como é que era o clima?". Este questionamento provocou um descrédito nessa possível explicação.

No EP 2 da mesma aula, os estudantes continuaram engajados em encontrar explicações para os padrões observados no gráfico. Assim como no grupo A, um dos estudantes sugeriu a proximidade da luminária como um fator que teria favorecido o alto crescimento da população. No entanto uma das colegas questionou essa explicação: "Se a gente for colocar esse fator a gente tem que levar em conta os resultados dos outros grupos..."

Já no EP 3 da Aula 14, o monitor participou da discussão fornecendo elementos para validar a relação entre alto crescimento e incidência direta da luz: "Por mais que você não tenha contado os outros, você não pode dizer que visualmente identificaram que o de vocês cresceu mais e que vocês acham que isso aconteceu por causa da luz?" 
Na aula 14 - EP 4, a professora passou a participar da discussão sobre as explicações que poderiam ser utilizadas para interpretar os padrões visualizados pela análise do gráfico. O grupo atribuiu o crescimento contínuo da população evidenciado pela reta média à intensidade luminosa que incidiu sobre seu microambiente e relacionou o momento em que houve queda da população com o processo de senescência dos indivíduos: "Mas nesse ponto podia ter algumas plantas mães quase para morrer".

As Figuras 10 e 11 representam o continnum EE performado pelos grupos A e C, respectivamente. Delas podemos inferir que os estudantes precisaram usar e construir diferentes inscrições (fotos, desenhos, tabelas e gráficos) durante o processo de investigação.

No trabalho de proposição do continuum EE, Kelly e Duschl (2002) argumentam que as atividades que visam promover as práticas epistêmicas precisam constituir um ambiente de aprendizagem no qual o uso pelos estudantes de vários dispositivos de inscrição se faça necessário, pois estes representam e comunicam dados e informações.

Wu e Krajcik (2006) denominam essas práticas sociais associadas ao uso de dispositivos de inscrição de "práticas de inscrição", que consistem em construir inscrições para expressar ideias numa determinada investigação, interpretar seu significado em diferentes contextos, usá-las para explicar fenômenos, fazer previsões e comunicar resultados de uma pesquisa. Esses autores realizaram um estudo de caso sobre as práticas de inscrição em duas sequências de ensino baseadas em investigação e concluíram que esse tipo de intervenção didática permite aos alunos compreender a relação entre inscrições, conceitos e o processo investigativo. Prain e Tytler (2012) defendem que as práticas de inscrição pelos estudantes não devem ser vistas apenas como ferramenta para a aprendizagem de conceitos, mas sim como promotoras da aprendizagem das formas de trabalho da ciência, pois esse tipo de prática é consistente com a forma como o conhecimento é produzido e comunicado na comunidade científica.

As Figuras 8 e 9 também nos mostram que embora os dois grupos tenham trabalhado com a mesma pergunta de investigação e executado os mesmos procedimentos iniciais para a coleta de dados (caracterizando uma atividade de ensino por investigação do tipo guiado), cada grupo performou um continuum EE com características específicas: seja em relação aos elementos das tabelas, gráficos e explicações resultantes de cada transformação, seja em relação aos momentos nos quais essas transformações ocorreram.

Essas características distintas podem ser consequências das primeiras decisões tomadas, como também das características dos dados obtidos por cada grupo. O trabalho de Silva e Trivelato (2017), por exemplo, demonstra que, a depender do ajuste dos dados a um determinado modelo teórico já conhecido, os alunos lidam com problemas distintos e, consequentemente, se engajam em práticas epistêmicas diferentes. O grupo A, por exemplo, vivenciou um processo de investigação no qual a transformação T1 precisou ser revista e retomada nas aulas 12 e 13, visto que ao iniciar a transformação T2, as alunas conseguiram visualizar padrões e, por conseguinte, identificaram dados anômalos a eles. 
Esse processo de refazer as transformações T1 e, de forma imbricada, as transformações T2, se estendeu até a última aula destinada à produção do relatório científico, restando às alunas pouco tempo para a elaboração de explicações para os padrões encontrados. Isso pode ter influenciado a ausência de explicações mais apropriadas para a complexidade da dinâmica populacional observada pelo grupo (Figura 8).

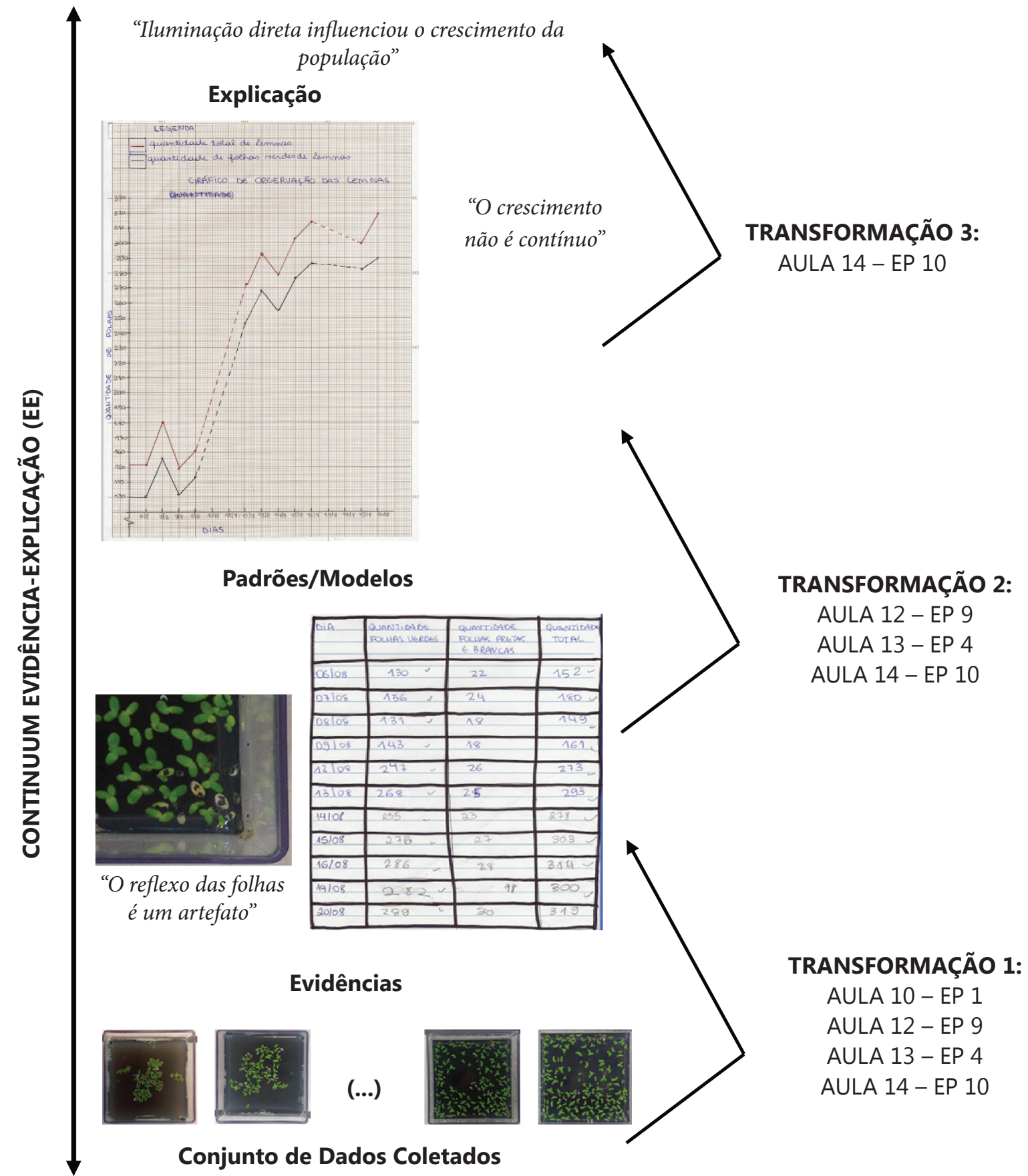

Figura 8. Continuum EE performado pelas estudantes do grupo A. À esquerda estão inseridas as inscrições produzidas pelas alunas e, à direita, os episódios nos quais identificamos as referidas transformações 
Por outro lado, o continuum vivenciado pelo grupo $\mathrm{C}$ revelou que os estudantes desse grupo não revisitaram as transformações T1 e T2 em outros episódios com maior ocorrência de diferentes práticas epistêmicas subsequentes à aula 10. Por conseguinte, os estudantes desse grupo puderam destinar um período maior da aula 14 para a elaboração de explicações para os padrões encontrados, o que resultou em um conjunto de explicações que abarca melhor a complexidade da dinâmica populacional observada pelo grupo (Figura 9).

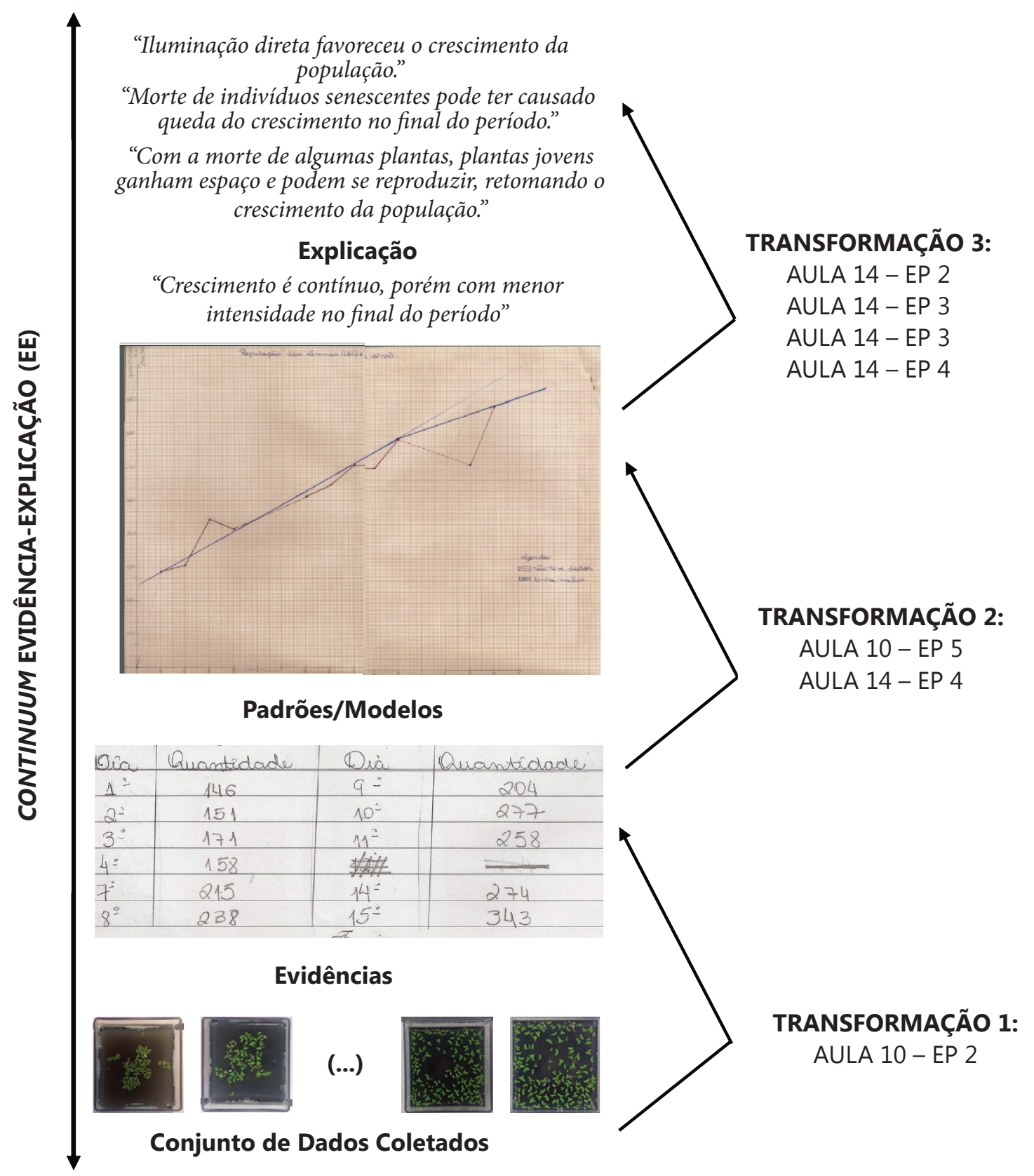

Figura 9. Continuum EE performado pelas estudantes do grupo C. À esquerda estão inseridas as inscrições produzidas pelos estudantes, à direita, os episódios nos quais identificamos as referidas transformações 
Esses diferentes percursos indicam que os grupos tiveram autonomia para guiar suas investigações. Conforme evidenciado nesta discussão e nas Figuras 5 e 6, as transformações do continuum $\mathrm{EE}$ foram realizadas em momentos distintos e de maneira não linear nos grupos analisados, o que reforça o argumento que os grupos realizaram as transformações necessárias à investigação de acordo com um fluxo próprio de ideias e uma dinâmica particular de condução da investigação. Essa dinâmica encontrada se relaciona à defesa de Prain e Tytler (2012) de que as atividades investigativas nas quais os alunos constroem suas próprias inscrições e as utilizam de forma autônoma e flexível, podem promover uma aprendizagem científica de qualidade.

\section{A autonomia para a tomada de decisão pelos estudantes}

Como apresentado anteriormente, Kelly e Duschl (2002) argumentam que as transformações do continuum EE representam uma oportunidade para o engajamento em práticas epistêmicas, uma vez que essas exigem que os estudantes definam o que é válido como evidência, padrão/modelo e explicação. Assim, tínhamos como hipótese que, se verificássemos a existência de coincidência entre os momentos de maior ocorrência de diferentes categorias de práticas epistêmicas com os momentos de transformação do continuum EE, encontraríamos também episódios de interação discursiva com alto nível de abertura para a tomada de decisão dos estudantes a respeito da investigação conduzida.

As Figuras 10 e 11 caracterizam as interações discursivas dos episódios nos quais evidenciamos a relação entre maior ocorrência de diferentes práticas epistêmicas e as transformações do continuum EE de cada grupo (A e C). Para cada um desses episódios verificamos se houve o estabelecimento explícito de um consenso (presença de práticas epistêmicas de legitimação). Quando houve, identificamos se houve a participação da professora ou do monitor na interação discursiva e, por fim, quem propôs a ação que se converteu em consenso.

\begin{tabular}{|c|c|c|c|c|}
\hline \multicolumn{2}{|c|}{$\begin{array}{l}\text { Episódios com mais de } \\
\text { quatro práticas epistêmicas }\end{array}$} & \multirow{2}{*}{$\begin{array}{l}\text { Há definição explícita } \\
\text { de consenso? } \\
\text { Sim } \\
\end{array}$} & \multirow{2}{*}{$\begin{array}{l}\text { Professora participa } \\
\text { da interação } \\
\text { discursiva? }\end{array}$} & \multirow{2}{*}{$\begin{array}{l}\text { Sujeito que propõe } \\
\text { ação - decisão }\end{array}$} \\
\hline \multirow{3}{*}{$\mathrm{T} 1$} & Aula 10 - EP 1 & & & \\
\hline & Aula 12 - EP 9 & Sim & Sim & Estudante \\
\hline & Aula 13 - EP 4 & Sim & Não & Estudante \\
\hline \multirow{3}{*}{$\mathrm{T} 2$} & Aula 12 - EP 9 & Sim & Sim & Estudante \\
\hline & Aula 13 - EP 4 & Sim & Não & Estudante \\
\hline & Aula 14 - EP 10 & Sim & Não & Estudante \\
\hline $\mathrm{T} 3$ & Aula 14 - EP 10 & Sim & Não & Estudante \\
\hline
\end{tabular}

Figura 10. Caracterização das interações discursivas associadas às transformações do continuum EE no grupo A 


\begin{tabular}{|c|c|c|c|c|}
\hline \multicolumn{2}{|c|}{$\begin{array}{l}\text { Episódios com mais de } \\
\text { quatro práticas epistêmicas }\end{array}$} & \multirow{2}{*}{$\begin{array}{l}\text { Há definição explícita } \\
\text { de consenso? }\end{array}$} & \multirow{2}{*}{$\begin{array}{l}\text { Professora participa } \\
\text { da interação } \\
\text { discursiva? }\end{array}$} & \multirow{2}{*}{$\begin{array}{l}\text { Sujeito que propõe } \\
\text { ação - decisão }\end{array}$} \\
\hline T1 & Aula 10 - EP 2 & & & \\
\hline \multirow{2}{*}{$\mathrm{T} 2$} & Aula 10 - EP 5 & Sim & Sim & Estudante \\
\hline & Aula 14 - EP 4 & Sim & Sim & Professora \\
\hline \multirow{4}{*}{ T3 } & Aula 14 - EP 1 & Não & Monitor & - \\
\hline & Aula 14 - EP 2 & Não & Não & - \\
\hline & Aula 14 - EP 3 & Sim & Monitor & Estudante \\
\hline & Aula 14 - EP 4 & Sim & Sim & Estudante \\
\hline
\end{tabular}

Figura 11. Caracterização das interações discursivas associadas às transformações do continuum EE no grupo C

A caracterização das interações discursivas nos momentos de transformação do continuum EE nos revelou que essas também eram constituídas por momentos de tomada de decisão, visto que observamos a ocorrência de duas categorias de práticas epistêmicas de legitimação relacionadas às ações de construção de consensos (Construir consenso de grupo sobre procedimentos e/ou Construir consenso de grupo para explicações científicas) em 12 dos 14 episódios analisados.

Nos episódios nos quais não identificamos a tomada de decisão (EP 1 e EP 2 da Aula 14 - Grupo C) os estudantes estavam discutindo sobre a validade das explicações propostas pelos colegas, mas não conseguiram construir um consenso sem a mediação da professora, o que ocorreu apenas no EP 4 da Aula 14.

A análise das Figuras 10 e 11 também evidencia que, nos trechos com tomada de decisão, a proposição da ação adotada como consenso final foi feita pelos estudantes, com exceção de apenas uma situação no grupo C (T2 - Aula 14 - EP 4).

Esses dados corroboram a validade de nossa segunda hipótese de trabalho, segundo a qual os episódios com maior diversidade de práticas epistêmicas estariam também associados às situações de autonomia para a tomada de decisões.

A seguir, descreveremos os três contextos de tomada de decisão caracterizados nas Figuras 10 e 11: sem a participação da professora ou monitor, com a participação da professora ou monitor e com consenso estabelecido a partir da proposição da professora e com a participação da professora e com consenso estabelecido a partir da proposição de um estudante.

Nos episódios dos quais a professora e o monitor (sujeitos de autoridade epistêmica) não participaram das discussões, todas as decisões foram tomadas pelos estudantes de forma autônoma.

Esse é o caso do EP 4 da Aula 13, no qual as estudantes do grupo A estavam engajadas na transformação T2, buscando decidir como representar as evidências obtidas pelo grupo a partir da construção de gráficos. Neste episódio, as alunas estavam construindo um único plano cartesiano para representar duas curvas distintas (indivíduos vivos - verdes e indivíduos mortos - pretos e brancos). Ao iniciar a construção do gráfico 
as estudantes se depararam com uma dificuldade metodológica devido à escala adotada. A conversação na Figura 12 refere-se a esse momento:

\begin{tabular}{|l|l|}
\hline Locutor & Transcrição \\
\hline Camila & $\begin{array}{l}\text { Então diminuiu... Olha, só pra saber um negócio, nós vamos fazer o gráfico de quantidade } \\
\text { de folhas pretas e brancas? }\end{array}$ \\
\hline Juliana & Isso. \\
\hline Camila & Então não vai poder ser nesse mesmo gráfico, porque esse aqui começa com $130 \ldots$ \\
\hline Juliana & Não, a gente vai fazer dois gráficos... \\
\hline Camila & Então eu vou fazer dois gráficos... \\
\hline Juliana & Um com folha verde... \\
\hline Camila & $\begin{array}{l}\text { E a quantidade total com uma cor diferente... E um outro menor com as folhas pretas e } \\
\text { brancas. }\end{array}$ \\
\hline
\end{tabular}

Figura 12. Excerto conversacional. Grupo A - Aula 13 - EP 4

Inicialmente, Camila se certificou da decisão anterior do grupo de representar a curva de indivíduos mortos ("folhas pretas e brancas") e, após a confirmação dada por Juliana, apresentou o problema metodológico devido à escala adotada. Em seguida, mesmo na ausência de um sujeito de autoridade epistêmica, vemos que as estudantes construíram o consenso de construir dois gráficos separadamente, visto que a escala não era adequada para expressar as diferentes curvas no mesmo plano cartesiano.

Kelly (2008) argumenta que o professor representa uma autoridade epistêmica em sala de aula fundamental para ajudar os aprendizes e moderar discussões. Nos episódios nos quais a professora ou o monitor participaram das discussões, em apenas um deles foi a própria professora que propôs a estratégia que se converteu em consenso (Grupo C - T2 - Aula 14 - EP 4). Nesse momento, a professora simulou a construção de uma reta média no gráfico já construído pelo grupo para possibilitar que os estudantes visualizassem outro padrão: o declínio da taxa de crescimento da população de Lemnas nos últimos dias da investigação (Figura 13).

\begin{tabular}{|l|l|}
\hline Locutor & Transcrição \\
\hline Professora & E se a gente fosse traçar aquela linha média? Como vocês fariam? \\
\hline Gisele & Reto... \\
\hline Professora & $\begin{array}{l}\text { Reto, reto? Olha, podemos excluir esse ponto e excluindo esse ponto porque eles } \\
\text { ficaram muito fora, né? Um ponto só fora, seria uma reta assim, que já junta quase } \\
\text { todos os outros pontos, entendeu? E aqui? Se eu continuasse aqui, olha onde ia a reta } \\
\text { (a professora faz demonstrações desenhando no gráfico) }\end{array}$ \\
\hline Professora & $\begin{array}{l}\text { Deve estar... Aí começou a estabilizar... } \\
\text { Exatamente. Então se vocês pensarem numa linha reta, vocês têm... Acho até que } \\
\text { outra tendência aqui, excluindo esse ponto e esse ponto... Então, por que que ela } \\
\text { cresceu tanto assim? Porque ela tinha todas as condições ideais para se desenvolver, } \\
\text { como vocês estavam falando. Por que ela começou a estabilizar? }\end{array}$ \\
\hline
\end{tabular}

Figura 13. Excerto conversacional. Grupo C - Aula 10 - EP 4 
Embora o trecho conversacional da Figura 14 não explicite o consenso, é possível observar na Figura 9, no continuum EE performado pelos estudantes do grupo C, que o gráfico final apresenta em vermelho as primeiras evidências produzidas pelo grupo e, em azul, a reta média indicando dois padrões: um crescimento mais acentuado no início da investigação e o início de uma estabilização no período final. Assim, considerando o gráfico elaborado pelo grupo, podemos considerar que a proposta da professora foi adotada como consenso do grupo.

Nas demais situações nas quais a professora ou o monitor participaram da interação, mesmo na presença de uma autoridade epistêmica, os estudantes propuseram ações para executar as transformações do continuum, ações estas que posteriormente foram legitimadas pelo grupo e/ou pela professora ou monitor. No excerto da Figura 14, representamos uma situação como essa (vivenciada pelo Grupo C na transformação T3 da Aula 14 - EP 4); nela os alunos estavam engajados na transformação T3, buscando decidir a validade das explicações para os padrões encontrados no gráfico.

\begin{tabular}{|l|l|}
\hline Locutor & Transcrição \\
\hline Vinícius & Mas a gente vai ter que explicar isso como? Pode dar palpites? \\
\hline Professora & Pode... Qual que é seu palpite? \\
\hline Vinícius & O clima... \\
\hline Professora & O clima? Mas alguém tem outro palpite? \\
\hline Vinícius & $($ ) \\
\hline Gisele & $\begin{array}{l}\text { Olha, esse é antes do... Do fim de semana, então... Porque a gente não sabe se aqui que é } \\
\text { fim de semana caiu ou não... E aqui também... ((aponta para um momento do gráfico)) }\end{array}$ \\
\hline Vinícius & $\begin{array}{l}\text { Aqui você já pode ter colocado água em excesso? ((aponta para um momento do } \\
\text { gráfico)) }\end{array}$ \\
\hline Professora & Não porque eu só coloquei água depois do final de semana... \\
\hline Bruno & $\begin{array}{l}\text { Mas nesse ponto podia ter algumas plantas mães quase pra morrer, daí chegaram as } \\
\text { filhas e (ocuparam)... ((aponta para pontos do gráfico)) }\end{array}$ \\
\hline Vinícius & O quê? \\
\hline Professora & $\begin{array}{l}\text { Então tem algumas plantas aqui... Tinham algumas plantas que estavam quase para } \\
\text { morrer, então quando a gente colocou a planta elas já estavam meio velhas... Então } \\
\text { algumas morreram. Aqui algumas também já estavam para morrer e elas morreram. } \\
\text { Pode ser... Tá? E aí depois dessa queda teve um surto de crescimento... O que explica } \\
\text { isso? }\end{array}$ \\
\hline Luana & Que algumas morreram e sobrou espaço? \\
\hline Gisele & Que o clima tava... \\
\hline Professora & Já que algumas morreram... \\
\hline Gisele & Teve mais espaço... \\
\hline Professora & Pode ser... Tudo bem? Então tá... Está bem legal! \\
\hline
\end{tabular}

Figura 14. Excerto conversacional. Grupo C - Aula 14 - Episódio 4

O excerto apresentado na Figura 14 ilustra o processo de tomada de decisão 
deste grupo sobre as explicações coerentes com os padrões no gráfico. Para explicar a queda populacional, os alunos estavam propondo hipóteses tais como a influência do clima ou a possibilidade de um excesso de água ter prejudicado o desenvolvimento da população. Nesse momento, a professora participou da interação avaliando as propostas dos estudantes, até que o aluno Bruno relacionou o padrão à morte de alguns indivíduos devido à senescência. Para auxiliar a compreensão da proposta de Bruno, a professora fez uso do meta-discurso, isto é, ela utilizou, ou fez referência, ao discurso construído por um aluno em específico para construir o discurso científico e promover entendimento sobre um fenômeno. Kelly e Licona (2018) argumentam que a prática do meta-discurso consiste em um processo de legitimação do discurso dos estudantes que pode fomentar a participação e o engajamento desses com as práticas epistêmicas.

\section{Considerações finais}

Este trabalho pretende contribuir para o desenvolvimento de uma compreensão sobre a relação entre engajamento em práticas epistêmicas, as transformações e decisões necessárias ao processo investigativo e o nível de abertura para atuação dos estudantes no ensino por investigação.

Para tanto, partimos das hipóteses de que os episódios com maior diversidade de práticas epistêmicas estariam associados às transformações que os alunos performam ao longo do processo investigativo, e que os mesmos episódios indicariam alto grau de autonomia intelectual dos estudantes. Orientadas por essas hipóteses buscamos analisar a relação que a diversidade de práticas epistêmicas tem com as transformações do continuun EE e com a autonomia dos estudantes.

Nossos dados nos permitiram afirmar que episódios com grande diversidade de práticas epistêmicas foram também momentos em que ocorreram transformações e decisões do continuun EE. Obtivemos, ainda, resultados associando a diversidade de práticas epistêmicas com a autonomia dos estudantes para tomar decisões concernentes à investigação que estavam realizando.

A relação entre a autonomia dos estudantes, as transformações que se processam quando esses decidem o que conta como dado, evidência, padrão e explicação, e os aspectos epistêmicos evidenciados nas interações que estabelecem entre si e com a professora são características que não apenas nos ajudam a delimitar a concepção de ensino por investigação aqui assumida, mas, no contexto deste trabalho, forneceram evidências para reafirmarmos nossas hipóteses iniciais. A associação que verificamos, ainda que de maneira localizada, pode inspirar a proposição de sequências de ensino que invistam na autonomia dos estudantes para realizarem as transformações do conhecimento no processo investigativo.

Por fim, ressaltamos que neste trabalho também propusemos estratégias metodológicas para o tratamento dos dados que viabilizaram a articulação de três aspectos (práticas epistêmicas, transformações do continuun EE e nível de abertura/ autonomia), o que, acreditamos, é uma contribuição importante para a área de pesquisa. 
Com isso esperamos ampliar as possibilidades de análise das situações de sala de aula e aumentar a compreensão de sua complexidade.

\section{Agradecimentos}

Agradecemos à Escola de Aplicação da Faculdade de Educação da USP por autorizar a realização da pesquisa, aos pareceristas pelas sugestões no momento da revisão e aos colegas do GEPEB pela leitura da primeira versão e contribuições para a reformulação deste trabalho.

\section{Referências}

Anderson, R. D. (2002). Reforming Science Teaching: What Research says about inquiry. Journal of Science Teacher Education, 13(2), 1-12. https://doi.org/10.1023/A:1015171124982

Banchi, H., \& Bell, R. (2008). The many levels of inquiry. Science and Children, 46(2), 26-29. Carvalho, A. M. P. (2012). Os estágios nos cursos de licenciatura. São Paulo: Cengage Learning.

Dewey, J. (1916). Democracy and education: an introduction to the philosophy of education. New York: Macmillan.

Duschl, R. (2008). Science Education in Three-Part Harmony: Balancing Conceptual, Epistemic, and Social Learning Goals. Review of Research in Education, 32(1), 268-291. http:// doi.org/10.3102/0091732X07309371

Galembeck, P. T. (2010). O turno conversacional. In D. Preti (Org.), Análise de textos orais. (pp. 65-92). São Paulo: Humanitas.

Hodson, D. (2014). Learning science, learning about science, doing science: Different goals demand different learning methods. International Journal of Science Education, 36(15), 25342553. https://doi.org/10.1080/09500693.2014.899722

Jiménez-Aleixandre, M. P. (2014). Determinism and Underdetermination in Genetics: Implications for Students' Engagement in Argumentation and Epistemic Practices. Science \& Education, 23(2), 465-484. http://dx.doi.org/10.1007/s11191-012-9561-6

Jiménez-Aleixandre, M. P., \& Crujeiras, B. (2017). Epistemic Practices and Scientific Practices in Science Education. In K. S. Taber, \& B. Akpan (Org.). Science Education: An International Course Companion (pp. 69-80). Rotterdam: SensePublishers. https://doi.org/10.1007/978-946300-749-8_5

Jiménez-Aleixandre, M. P., Mortimer, F., Silva, A. C. T., \& Díaz, J. (2008). Epistemic practices: an analytical framework for science classrooms. In Annual American Educational Research Association. New York City, NY/EUA.

Kelly, G. J. (2008). Inquiry, activity, and epistemic practice. In R. A. Duschl, \& R. E. Grandy (Org). Teaching scientific inquiry. Recommendations for research and implementation (pp. 99117). Rotterdam: Sense Publishers. 
Kelly, G. J., \& Duschl, R. A. (2002). Toward a research agenda for epistemological studies in science education. In National Association for Research in Science Teaching Meeting, New Orleans, LA/EUA.

Kelly, G. J., \& Licona, P. (2018). Epistemic Practices and Science Education. In M. R. Matthews (Org.). History, Philosophy and Science Teaching: New Perspectives (pp. 139-165). Cham: Springer International Publishing. https://doi.org/10.1007/978-3-319-62616-1_5

Krasilchik, M., \& Marandino, M. (2007). Ensino de Ciências e Cidadania. São Paulo: Editora Moderna.

Martins, I. (2006). Dados como diálogo - construindo dados a partir de registros de observação de interações discursivas em salas de aula de ciências. In F. M. T. Santos, \& I. M. Greca (Org.). A pesquisa em ensino de ciências no Brasil e suas metodologias (pp. 297-321). Ijuí: Editora UNIJUI.

Minner, D. D., Levy, A. J., \& Century, J. (2010). Inquiry-based science instruction-what is it and does it matter? Results from a research synthesis years 1984 to 2002. Journal of Research in Science Teaching, 47(4), 474-496. http://dx.doi.org/10.1002/tea.20347

Mortimer, E. F., \& Araújo, A. O. (2014). Using productive disciplinary engagement and epistemic practices to evaluate a traditional Brazilian high school chemistry classroom. International Journal of Educational Research, 64, 156-169. https://doi.org/10.1016/j.ijer.2013.07.004

NRC (2000). Inquiry and the national science education standards: A guide for teaching and learning. Washington: National Academies Press.

Osborne, J. (2016). Defining a knowledge base for reasoning in science: the role of procedural and epistemic knowledge. In R. A. Duschl, \& A. S. Bismack (Org.). Reconceptualizing STEM education: the central role of practices (pp.215-231). New York: Routledge.

Sadeh, I., \& Zion, M. (2009). The development of dynamic inquiry performances within an open inquiry setting: A comparison to guided inquiry setting. Journal of Research in Science Teaching, 46(10), 1137-1160. http://doi.org/10.1002/tea.20310

Sadeh, I., \& Zion, M. (2012). Which Type of Inquiry Project Do High School Biology Students Prefer: Open or Guided?. Research in Science Education, 42(5), 831-848. https://doi.org/10.1007/ s11165-011-9222-9

SEE-SP (2008). Proposta Curricular do Estado de São Paulo: Biologia. M. I. Fini (Coord.). São Paulo: SEE, 2008.

Scarpa, D. L., \& Silva, M. B. (2013). A Biologia e o ensino de Ciências por investigação: dificuldades e possibilidades. In A. M. P. Carvalho (Org.). Ensino de Ciências por investigação: condições para implementação em sala de aula (pp. 129-152). São Paulo: Cengange Learning.

Scarpa, D. L., Sasseron, L. H., \& Silva, M. B. (2017). O Ensino por Investigação e a Argumentação em Aulas de Ciências Naturais. Tópicos Educacionais, 23(1), 7-27.

Schwab, J. J. (1962). The teaching of science as inquiry. In J. J. Schwab \& P. F. Brandwein (Org.). The teaching of science (pp. 1-103). Massachusetts: Harvard University Press. 
Silva, A. C. T. (2015). Interações discursivas e práticas epistêmicas em salas de aula de ciências. Ensaio: Pesquisa em Educação em Ciências, 17(spe), 69-96. https://dx.doi.org/10.1590/1983$2117201517 \mathrm{~s} 05$

Silva, M. B., \& Trivelato, S. L. F. (2016). Propiciando o engajamento em práticas epistêmicas da cultura científica: uma proposta de atividade investigativa sobre dinâmica populacional. Revista de Ensino de Biologia da Associação Brasileira de Ensino de Biologia (SBEnBio), 9, 4932-4941.

Silva, M. B., \& Trivelato, S. L. F, (2017). A mobilização do conhecimento teórico e empírico na produção de explicações e argumentos numa atividade investigativa de Biologia. Investigações em Ensino de Ciências, 22(2), 139-153. http://doi.org/10.22600/1518-8795.ienci2017v22n2p139 Silverman, D (2000). Doing qualitative research: a practical handbook. London: Sage.

Tamir, P. (1977). How are the laboratories used? Journal of Research in Science Teaching, 14(4), 311-316, 1977. http://dx.doi.org/10.1002/tea.3660140408

Wu, H. K., \& Krajcik, J. S. (2006). Exploring middle school students' use of inscriptions in project-based science classrooms. Science Education, 90(5), 852-873. http://doi.org/10.1002/ sce. 20154

Zion, M., \& Mendelovici, R. (2012). Moving from structured to open inquiry: Challenges and limits. Science Education International, 23(4), 383-399. 
Maíra Batistoni e Silva

${ }^{-}$http://orcid.org/0000-0002-5490-1862

Universidade de São Paulo Instituto de Biociências Departamento de Fisiologia São Paulo, Sáo Paulo, Brasil mbatistoni@usp.br

\section{Eloísa Cristina Gerolin}

${ }^{\circledR}$ http://orcid.org/0000-0001-9382-3812 Universidade de São Paulo

Faculdade de Educação Programa de Pós-graduação em Educação

São Paulo, São Paulo, Brasil eloisa.gerolin@usp.br

Sílvia L. Frateschi Trivelato

${ }^{\circledR}$ http://orcid.org/0000-0002-3444-7359 Universidade de São Paulo Faculdade de Educação Departamento de Metodologia do Ensino e Educação Comparada São Paulo, São Paulo, Brasil slftrive@usp.br

Submetido em 31 de Janeiro de 2018 Aceito em 13 de Agosto de 2018 Publicado em 15 de Dezembro de 2018 